\title{
The Investigation of NiCuZn Ferrites Prepared by Using Nano-Size ZnO
}

\author{
Jiwei Fan ${ }^{*}$, Zhihui Zhang ${ }^{b}$, Xiaoli Zhang ${ }^{\mathrm{c}}$, Huijun Zhao ${ }^{\mathrm{d}}$
}

School of Materials and Chemical Engineering, Zhongyuan University of Technology, Zhengzhou, 450007, China

${ }^{* a}$ Corresponding author, email:jeff51@163.com ; bemail: 719822137@qq.com;

cemail: karer2004@163.com; demail: zhj@zzti.edu.cn

\begin{abstract}
Keywords: NiCuZn Ferrite, Nano-ZnO, Resistivity, Coercivity, Power loss
Abstract. The present work reported and discussed the results of investigation of employing nano- $\mathrm{ZnO}$ and general $\mathrm{ZnO}$ (AR grade) to prepare $\mathrm{Ni}_{0.15} \mathrm{Cu}_{0.35} \mathrm{Zn}_{0.5} \mathrm{Fe}_{2} \mathrm{O}_{4}$ ferrites. The samples were prepared by using conventional ceramic processing route and sintered between $1150-1250^{\circ} \mathrm{C}$. The comparison of sintered samples made by employing nano- $\mathrm{ZnO}$ and made by employing general $\mathrm{ZnO}$ powder shows that the use of nano- $\mathrm{ZnO}$ could increase the chemical activity of starting materials, improve the densification and homogeneity of sintered bodies, enhance the electrical and magnetic properties of $\mathrm{NiCuZn}$ ferrites.
\end{abstract}

\section{Introduction}

$\mathrm{NiCuZn}$ ferrites are used widely as magnetic devices in telecommunication and electronic industries because they possess excellent magnetic properties suitable for working at high frequency[1-4].. Particularly, they can be produced by simple ceramic processing under lower sintering temperature and without the requirement of controlling sintering atmosphere.

It is well known that the properties of ferrites are mainly controlled by composition, starting materials and employed processing method. Recently, many commercial nano-chemicals have been produced with the development of nanotechnology. However, little systematic study has been carried out on the effects of using nano-chemicals on the processing of $\mathrm{NiCuZn}$ ferrites, especially their magnetic and electrical properties. The present work shows the results of investigation on the influence of employing nano- $\mathrm{ZnO}$ in a typical $\mathrm{NiCuZn}$ ferrite composition, comparison of its sintered density, resistivity, power loss and microstructure with the NiCuZn ferrites produced by using general chemicals.

\section{Experimental Procedures}

Sample Preparation. The ferrite samples used in this study were based on a typically commercial formula: $\mathrm{Ni}_{0.15} \mathrm{Cu}_{0.35} \mathrm{Zn}_{0.5} \mathrm{Fe}_{2} \mathrm{O}_{4}$. All starting materials were analytic grade oxides, the average particle size of nano- $\mathrm{ZnO}$ is about $60 \mathrm{~nm}$. They were mixed in deionised water with agate balls for 20 hours by ball milling. After drying, granules were obtained by passing the dried powders through a screen having an aperture mesh of nominally $0.3 \mathrm{~mm}$. The small disc shape samples $(12 \mathrm{~mm}$ diameter, $3 \mathrm{~mm}$ height.) and the toroid samples $(25 \mathrm{~mm}$ outside diameter, $18 \mathrm{~mm}$ inside diameter, and $3 \mathrm{~mm}$ height) were pressed by a uniaxial press at $80 \mathrm{MPa}$. The samples were sintered at 1150,1200 and $1250^{\circ} \mathrm{C}$ for 2 hours in air respectively, with both heating and cooling rates at $3{ }^{\circ} \mathrm{C} / \mathrm{min}$. The samples prepared by general chemicals were designated as $\mathrm{G}$ samples, and the samples prepared by nano-ZnO were designated as $\mathrm{N}$ samples.

Characterization. The sintered densities of the samples were determined according to the mass and volume of sample. Before electrical measurements, sliver electrodes were applied to both sides of the disc samples. The resistances of disc samples were determined by using a LCR meter (Victor VC9018). The resistivities were computed out according to the measured resistances and the geometry of discs. The coercivity and power loss of sintered $\mathrm{NiCuZn}$ ferrite toroids were determined by using two windings (both primary and secondary coils are 50 turns) and sample geometries by an ac magnetic property measuring equipment (TY-2000A). The testing flux density 
is $0.08 \mathrm{~T}$ and the testing frequencies are $10 \mathrm{kHz}, 30 \mathrm{kHz}$ and $50 \mathrm{kHz}$ respectively. The microstructures of samples were examined by using a scanning electron microscope (JSM-6360LV) equipped with energy dispersive spectrometer (EDS).

\section{Results}

Sintered Density. Table 1 shows the comparison of sintered densities of samples at different sintering temperatures. It indicates that the samples prepared by nano- $\mathrm{ZnO}(\mathrm{N}$ sample) could achieve higher densities at all sintering temperatures. Obviously, the nano-ZnO enhances the densification of $\mathrm{Ni}-\mathrm{Zn}$ ferrites.

Table 1 The sintered densities of samples

\begin{tabular}{cccc}
\hline Sintering Temperature $\left({ }^{\circ} \mathrm{C}\right)$ & 1150 & 1200 & 1250 \\
\hline Sintered Density for G Samples $\left(\mathrm{g} / \mathrm{cm}^{3}\right)$ & $4.60 \pm 0.02$ & $4.57 \pm 0.03$ & $4.61 \pm 0.02$ \\
\hline Sintered Density for N Samples $\left(\mathrm{g} / \mathrm{cm}^{3}\right)$ & $4.63 \pm 0.01$ & $4.62 \pm 0.02$ & $4.63 \pm 0.02$ \\
\hline
\end{tabular}

Resistivity. Fig.1 shows the resistivities of $\mathrm{NiCuZn}$ ferrite samples as a function of sintering temperatures. It can be seen that the resistivities of both samples decrease with the increase of sintering temperature, but the resistivities of $\mathrm{N}$ samples have the higher resistivities than those of $\mathrm{G}$ samples, which could be due to the effect of using nano- $\mathrm{ZnO}$.

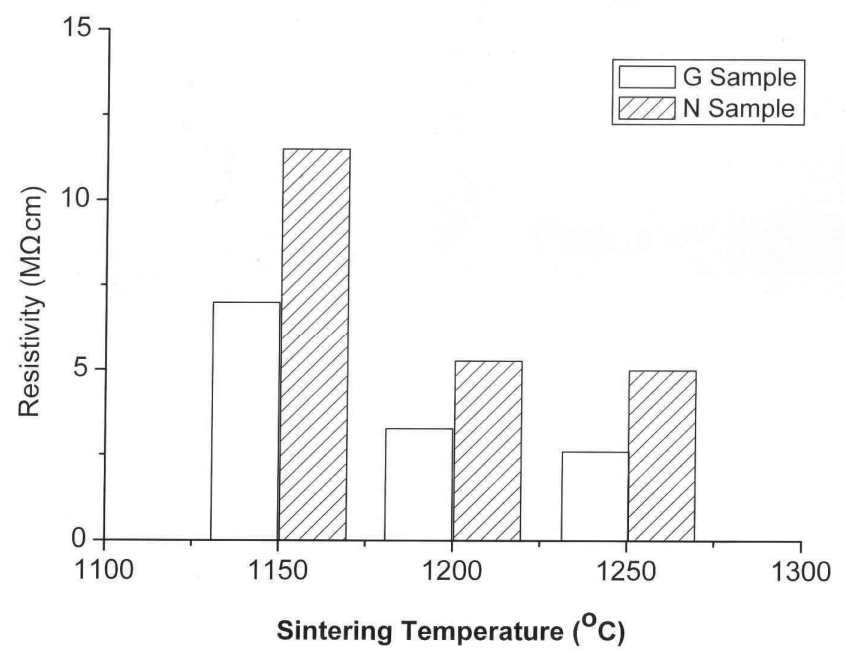

Fig. 1 The resistivity of samples

The coercivity and power loss. The coercivity and power loss are two of important magnetic properties for soft ferrites. The coercivity and power loss of both NiCuZn ferrite samples sintered at $1250^{\circ} \mathrm{C}$ under different testing frequencies are shown in Fig. 2 and Fig.3, respectively. It is obvious that the samples made by using nano-ZnO ( $\mathrm{N}$ sample) have lower coercivity and power loss than those of general samples ( $\mathrm{G}$ sample). The testing frequencies were $10 \mathrm{kHz}, 30 \mathrm{kHz}$ and $50 \mathrm{kHz}$ respectively. From Fig.2, it can be seen that the coercivities of samples are nearly no change under different testing frequencies. However, the power loss of samples increases with the raised testing frequencies significantly (Fig.3). 


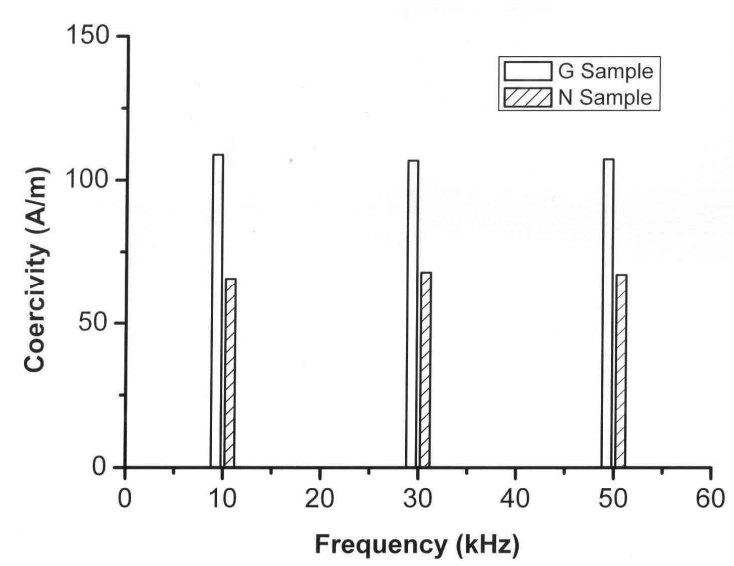

Fig. 2 The coercivity of samples

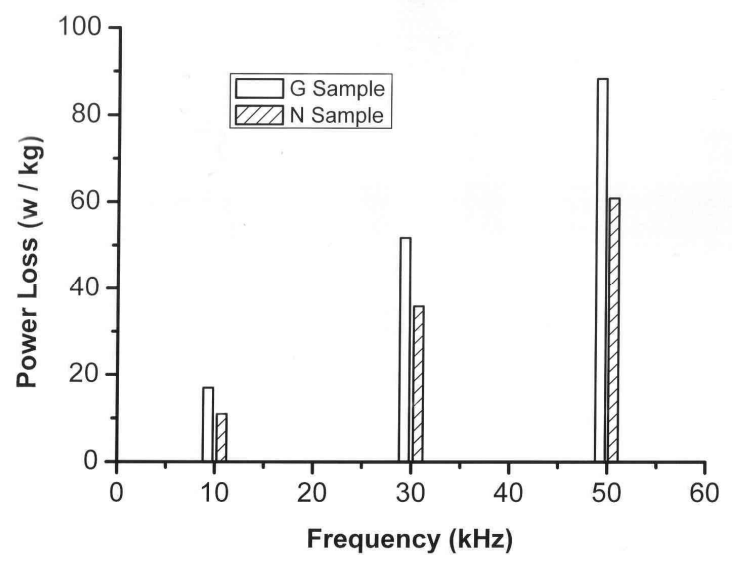

Fig. 3 The power loss of samples

Microstructure. The micrographs of fracture surface of samples sintered at $1250^{\circ} \mathrm{C}$ are shown in Fig.4. It can be seen that the grain size of both samples are similar, but $\mathrm{N}$ sample (Fig. $4 \mathrm{~b}$ ) is more uniform and the sintered body looks denser, which may be due to the higher chemical activity of nano- $\mathrm{ZnO}$. This may also be the reason of that why the sintered densities of $\mathrm{N}$ samples are higher than those of $\mathrm{G}$ samples.

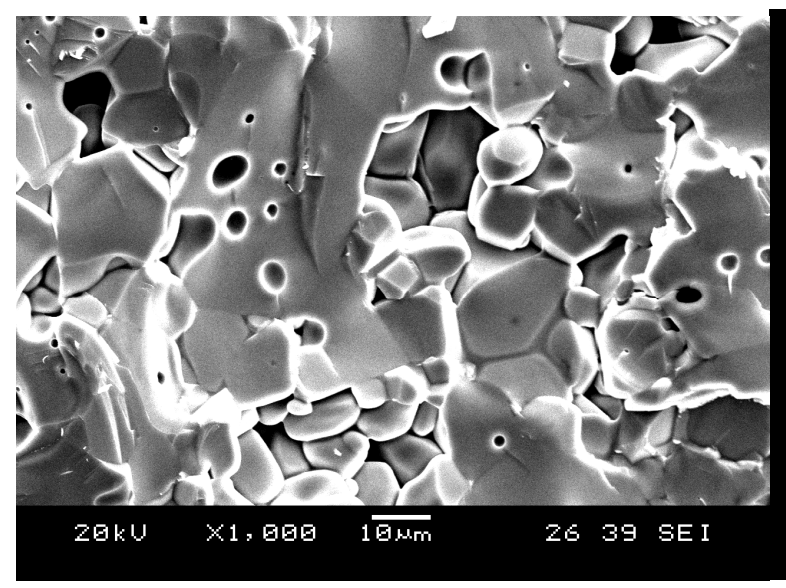

(a)

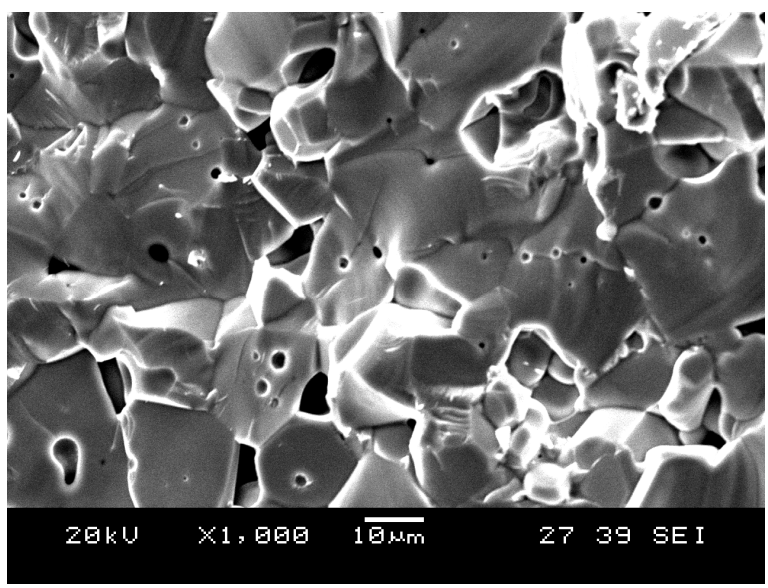

(b)

Fig. 4 Typical SEM micrographs of NiCuZn ferrites sintered at $1250^{\circ} \mathrm{C}$, (a) $\mathrm{G}$ sample; (b) $\mathrm{N}$ sample

\section{Discussion}

The coercivity and power loss are two of important magnetic properties for soft ferrites. Usually the influence factors for the coercivity are formulation, staring materials, processing route and the resulting microstructure. If the formulation and processing route are same, the ferrites with more uniform grain size have lower coercivity.[4-7] In this experiment, the samples made by using nano- $\mathrm{ZnO}$ ( $\mathrm{N}$ samples) have better uniformity, these may be attributed to the higher chemical activity of nano-ZnO powder. Therefore, they have lower coercivities than those of general samples.

Generally the power loss $\mathrm{P}_{\mathrm{L}}$ of ferrite materials consists of three components, i.e., the hysteresis loss $\mathrm{P}_{\mathrm{h}}$, eddy current loss $\mathrm{P}_{\mathrm{e}}$, and residual loss $\mathrm{P}_{\mathrm{r}}$. Since the residual loss $\mathrm{P}_{\mathrm{r}}$ is only of importance at very low induction levels or at high frequency $(>500 \mathrm{kHz})[8-10]$, the power loss can be expressed as following:

$$
\mathrm{P}_{\mathrm{L}}=\mathrm{P}_{\mathrm{h}}+\mathrm{P}_{\mathrm{e}}
$$

For the materials operating at typical frequencies $P_{h}$ and $P_{e}$ can be given as $[8,9,11]$ :

$$
\begin{aligned}
& P_{h}=C_{h} B^{3} f \\
& P_{e}=C_{e} B^{2} f^{2} / \rho
\end{aligned}
$$


where $C_{h}$, and $C_{e}$, are the coefficients for hysteresis loss and eddy current loss, respectively, B is flux density (Tesla), $\mathrm{f}$ is frequency $(\mathrm{kHz}), \mathrm{D}$ is the average grain size $(\mu \mathrm{m})$ and $\rho$ is resistivity $(\Omega \mathrm{m})$. Combining (2) and (3), the power loss can be expressed as:

$$
P_{L}=P_{h}+P_{e}=C_{h} B^{3} f+C B^{2} f^{2} D^{2} / \rho
$$

Since the testing flux density are fixed $(\mathrm{B}=0.08 \mathrm{~T})$, according to Equation $(4)$, it can be seen the influence factors to power loss are frequency $f$, average grain size $\mathrm{D}$ and resistivity $\rho$. The power loss is proportional to $\mathrm{f}$, therefore the samples have higher power losses at higher frequency. Moreover, since the average grain sizes for both samples are similar, therefore, the resistivity plays important role in power loss. The samples made by using nano- $\mathrm{ZnO}$ ( $\mathrm{N}$ samples) have much higher resistivities than those of $\mathrm{G}$ samples (refer Fig.1), hence $\mathrm{N}$ samples have less power losses are quite reasonable.

\section{Summary}

1. The sintered density and resistivity of $\mathrm{Ni}_{0.15} \mathrm{Cu}_{0.35} \mathrm{Zn}_{0.5} \mathrm{Fe}_{2} \mathrm{O}_{4}$ ferrite are strongly affected by sintering temperature.

2. The comparison of sintered samples made by using nano- $\mathrm{ZnO}$ ( $\mathrm{N}$ samples) and general $\mathrm{ZnO}$ powder ( $\mathrm{G}$ samples), the samples using nano-ZnO have higher sintered densities and resistivities, lower coercivities and less power losses.

3. The use of nano- $\mathrm{ZnO}$ increased the chemical activity, improved the densification and homogeneity, and enhanced the electrical and magnetic properties of $\mathrm{NiCuZn}$ ferrites.

\section{References}

[1] T. Araki, H. Morinaga, K.I. Kobayashi, T. Omura and K. Sato, Low loss NiCuZn ferrite for deflection yoke, Proc.ICF6, (1992) 1185-1187

[2] T. Suzuki, T. Nomura, Effect of impurities and firing condition on electromagnetic properties of low temperature sintered NiCuZn ferrites. [J]. J.Soc.Mater.Eng.Resour., Jpn. 6 (1993) 51-55

[3] B. P. Rao, A. M. A. Kumar, K. H. Rao, Y. L. N. Murthy, O. F. Caltun, I. Dumitruc, L. Spinu, Synthesis and magnetic studies of Ni-Zn ferrite nanoparticles, [J]. Journal of Optoelectronics and Advanced Materials, 8 (2006) 1703 -1705

[4] A. Goldman, Modern Ferrite Technology, New York, Van Nostrand Reinhold, 1990

[5] J. Fan, F.R.Sale, The Microstructures, Magnetic Properties and Impedance Analysis of Mn-Zn Ferrites Doped with $\mathrm{B}_{2} \mathrm{O}_{3}$, [J]. J.Eur.Ceram.Soc., 20 (2000) 2743-2751,

[6] J. Fan, F.-K. Ng, F.R.Sale, Magnetic Properties and Microstructure of $\mathrm{SnO}_{2}$ doped $\mathrm{Mn}-\mathrm{Zn}$ Ferrites, [J]. Rare Metals, 25 (2006) Sup., 445-449,

[7] J. Fan, W. Li, H. Zhao, X. Zhang, Z. Zhang, The Effects of Sintering Temperature on the Properties of Mg-Mn-Zn Ferrites, [J]. Advanced Materials Research, 680 (2013) 31-34

[8] J. Fan, F. R. Sale, Analysis of Power Loss on Mn-Zn Ferrites Prepared by Different Processing Routes, [J]. IEEE Transactions on Magnetics, 32 (1996) 4854-4856

[9] E. C. Snelling and A. D. Giles, Ferrites for Inductors and Transformers, Philips Research Laboratory, Redhill, Surry, England, 1983, 54-62

[10] T. Mochizuki, I. Sasaki and M.Torii, Mn-Zn ferrites for 400-600kHz switching power supplies, in Advances in Ceramics, vo1.16, (Ed. by F. Y. Wang), The American Ceramic Society, Columbus, USA. 1985, 487-492

[11] Th. G. W. Stijntjes and J. J. Roelofsma, Low-loss power ferrites for frequencies up to $500 \mathrm{kHz}$, in Advances in Ceramics, vo1.16, (Ed. by F. Y. Wang), The American Ceramic Society, Columbus, USA 1985, 493-500 